CLINICAL STUDY

\title{
Adipocytokine and ghrelin levels in relation to bone mineral density in physically active older women: longitudinal associations
}

\author{
Jaak Jürimäe ${ }^{1}$, Tatjana Kums ${ }^{2}$ and Toivo Jürimä ${ }^{1}$ \\ ${ }^{1}$ Institute of Sport Pedagogy and Coaching Sciences and ${ }^{2}$ Institute of Exercise Physiology and Physiotherapy, Centre of Behavioural and Health Sciences, \\ University of Tartu, 18, Ülikooli Street, Tartu 50090, Estonia \\ (Correspondence should be addressed to J Jürimäe; Email: jaakj@ut.ee)
}

\begin{abstract}
Purpose: We investigated the relationship between the decrease in bone mineral mass (BMC) and bone mineral density (BMD) values with baseline adipocytokine and ghrelin concentrations in physically active postmenopausal women.

Methods: Leptin, adiponectin, ghrelin, BMC, BMD and different body composition values were measured in 35 women (age: $69.7 \pm 6.0$ years) before and after a 12-month prospective study period. Results: Significant $(P<0.05)$ decreases in fat-free mass (FFM) (by $2.56 \%)$ and BMC (by $1.63 \%)$ and increases in adiponectin (by 14.8\%) were seen in older females as a result of the study period. The independent variables that were associated with decreases in total BMC were baseline fat mass (FM) and adiponectin explaining $30.6 \%\left(R^{2} \times 100\right)$ of the total variance. In another model, baseline FFM and leptin were the independent variables that explained $20.6 \%(P<0.05)$ of the total variance in the decreases in total BMD value. The variables that were associated with decreases in femoral neck BMD were FM and leptin $\left(R^{2}=0.102 ; P<0.05\right)$, while the independent variables were baseline trunk fat:leg fat ratio and adiponectin in the model with decreases in lumbar spine BMD as the dependent variable, and accounted for $13.1 \%(P<0.05)$ of the decreases in BMD variance.

Conclusions: Initial adiponectin concentration together with specific body composition characteristics predicted loss in BMC and lumbar spine BMD values, while initial leptin concentration together with specific body composition parameters determined the loss in total and femoral neck BMD values in physically active older women.
\end{abstract}

European Journal of Endocrinology $160381-385$

\section{Introduction}

Body mass has been considered as one of the strongest predictors of bone mineral mass (BMC) and bone mineral density (BMD) (1-3), and is inversely associated with postmenopausal bone loss and bone turnover $(4,5)$. It is also well established that appetite and food intake decline with ageing, resulting in body mass loss (6). Furthermore, ageing is characterised with changes in body composition, including a decrease in fat-free mass (FFM) and an increase in fat mass (FM) (6). A number of cross-sectional investigations have established a strong relationship between FM and BMD in women (7-9), especially after menopause $(10,11)$. The age-related loss of FFM, including BMC, is caused by a reduction in anabolic hormones, physical activity and appetite (6).

The protective effect of FM on bone may be mediated by the peripheral signals of appetite regulation and energy homeostasis (3, 6-8). Among the numerous adipose-modulated biochemical signals that may explain some of the association between FM and BMD in the elderly are leptin, adiponectin and the gut hormone ghrelin (11). Leptin, the product of LEP gene, regulates body mass by suppressing appetite and stimulating energy expenditure (12). Adiponectin is a polypeptide hormone expressed specifically and abundantly in adipose tissue and produced in visceral, s.c. and bone marrow fat depots (13), while ghrelin is secreted primarily by cells in the fundus of the stomach and plays a key role in the stimulation of the hypothalamic appetite centres (14) and in the coordination of feeding behaviour and energy metabolism (15). Accordingly, ghrelin has been reported to increase FM by stimulating appetite and reducing fat use (15). Circulating adiponectin $(3,16)$ and ghrelin $(17)$ have been shown to increase, while no changes in leptin (3) have been observed with menopause in women.

Leptin, adiponectin and ghrelin seem to play an important role in the regulation of body composition throughout life, but the mechanisms are not yet well understood (11). Furthermore, to our knowledge, no 
investigations have been conducted to longitudinally examine the possible role of adiponectin and ghrelin with BMC and BMD loss in healthy postmenopausal women. Therefore, we conducted a 12-month prospective study to investigate the relationship between loss in $\mathrm{BMC}$ and BMD values with baseline leptin, adiponectin and ghrelin concentrations. In addition, we evaluated different body composition values that are known to affect bone metabolism.

\section{Materials and methods}

\section{Subjects}

Thirty-five postmenopausal women aged between 60 and 81 years participated in this study. They were taking part in the 60-min gymnastics lessons twice a week and had been doing so for at least the last 5 years. All subjects signed an informed consent that was approved by the Medical Ethics Committee of the University of Tartu, Tartu, Estonia. Prior to study enrolment, volunteers completed medical and physical activity questionnaires. They were excluded from the study, if they reported present or previous conditions that might have interfered with bone metabolism (such as heart disease, long-term corticosteroid use, smoking and alcoholism). At the time of the study period, no participants were receiving treatments such as calcium, vitamin $\mathrm{D}$, calcitonin, bisphosphonates and diuretics, which could influence bone mineral values $(2,7,18)$. If the participants had received hormone replacement therapy, they were also excluded from the study.

\section{Experimental design}

This study was a 12-month prospective study. All participants were tested twice, at the beginning of the study and 12 months later. At both times, all women were asked to come for two visits to complete the testing. On the first visit, participants had anthropometric parameters measured and a venous blood sample was taken in the morning after a 10-hour fast. The second measurement session consisted of body composition and bone mineral assessments by dual energy X-ray absorptiometry (DXA). Measurement sessions were separated by approximately 1 week depending on the participant's schedule and DXA availability.

\section{Anthropometric, body composition and bone mineral measurements}

Height was measured using a Martin metal anthropometer to the nearest $0.1 \mathrm{~cm}$ with a standard technique. Body mass was measured with minimal clothing to the nearest $0.05 \mathrm{~kg}$ using a medical electronic scale (A\&D Instruments, Oxfordshire, UK) and body mass index (BMI) was calculated as body mass (in $\mathrm{kg}$ ) divided by height (in $\mathrm{m}^{2}$ ). Whole body fat, lean and BMC were measured by DXA using the DPX-IQ densitometer (Lunar Corporation, Madison, WI, USA) equipped with adult, proprietary software, version 3.6. Participants were scanned in light clothing while lying flat on their backs with arms at their sides. The standard participant positioning was used for total body measurements and analysed using the extended analysis option. The standard manufacturer's skeletal landmarks were used to define trunk and leg fat. Body fat distribution was calculated as the ratio of trunk fat (in $\mathrm{kg}$ ) to leg fat (in $\mathrm{kg}$ ) $(8,19)$. BMD was determined as the total body BMD and at the skeletal sites of posterioranterior spine (L2-L4) and femoral neck $(2,8)$. Coefficients of variation (CV) for measured FM, FFM, BMC and BMD parameters were less than $2 \%$.

\section{Blood sampling and analysis}

A $10 \mathrm{ml}$ blood sample was obtained from the antecubital vein in the morning $(0700-0800 \mathrm{~h})$ after an overnight fast. Plasma was separated and frozen at $-20{ }^{\circ} \mathrm{C}$ for later analysis. Total ghrelin concentration was determined in duplicate using a commercially available RIA kit (Linco Research, St Charles, MO, USA). The sensitivity of this kit was $93 \mathrm{pg} / \mathrm{ml}$, and the intraand inter-assay $\mathrm{CV}$ values were $<10 \%$ and $14.7 \%$ respectively. Total adiponectin concentration was assessed in duplicate using a commercially available RIA kit (cat. no. HADP-61 HK; Linco Research, USA). The intra- and inter-assay CV values were $<7 \%$. Leptin concentration was also determined in duplicate by RIA (Mediagnost $\mathrm{GmbH}$, Reutlingen, Germany). This assay has the intra- and inter-assay CV values of less than 5\%.

\section{Statistical analysis}

Statistical analysis was performed with SPSS 13.0 for Windows (Chicago, IL, USA), and the means ( \pm s.D.) were determined. Paired $t$-tests were performed to determine the changes in measured variables over the 12-month study period. The least significant change (LSC) for measured BMD variables was also calculated (20) resulting in an LSC of $3 \%$ at the measured sites. Pearson correlation coefficients were computed to explore the relationship between changes in bone mineral values during a 12-month study period with baseline body composition and blood biochemical variables. Backward regression elimination procedures were also used to evaluate potential associations of a decrease in bone mineral values with several baselineindependent variables. Significance was set at $P<0.05$.

\section{Results}

The mean ( \pm S.D.) of measured characteristics for studied older females (age: 69.7 \pm 6.0 years) before 
Table 1 Mean ( \pm S.D.) of subject characteristics before and after a 12-month study period $(n=35)$.

\begin{tabular}{|c|c|c|c|}
\hline Variables & Before & After & $P$ value \\
\hline Height (cm) & $160.0 \pm 5.6$ & $159.8 \pm 5.7$ & 0.081 \\
\hline Body mass (kg) & $67.6 \pm 9.0$ & $67.2 \pm 8.9$ & 0.623 \\
\hline BMI $\left(\mathrm{kg} / \mathrm{m}^{2}\right)$ & $26.3 \pm 3.7$ & $26.0 \pm 3.7$ & 0.133 \\
\hline $\begin{array}{l}\text { Percentage of } \\
\text { FM }\end{array}$ & $35.9 \pm 7.0$ & $35.9 \pm 6.1$ & 0.971 \\
\hline FM (kg) & $24.1 \pm 7.1$ & $24.3 \pm 6.6$ & 0.625 \\
\hline Trunk fat $(\mathrm{kg})$ & $11.2 \pm 3.2$ & $11.3 \pm 3.1$ & 0.170 \\
\hline $\begin{array}{l}\text { Trunk fat:leg fat } \\
\text { ratio }\end{array}$ & $1.61 \pm 0.28$ & $1.62 \pm 0.27$ & 0.146 \\
\hline FFM (kg) & $43.0 \pm 3.3$ & $41.9 \pm 3.2$ & 0.001 \\
\hline $\begin{array}{l}\text { Total body } \\
\text { BMC (kg) }\end{array}$ & $2.5 \pm 0.4$ & $2.4 \pm 0.4$ & 0.001 \\
\hline $\begin{array}{l}\text { Total body } \\
\text { BMD }\left(\mathrm{g} / \mathrm{cm}^{2}\right)\end{array}$ & $1.075 \pm 0.087$ & $1.067 \pm 0.089$ & 0.312 \\
\hline $\begin{array}{l}\text { Femoral neck } \\
\text { BMD }\left(\mathrm{g} / \mathrm{cm}^{2}\right)\end{array}$ & $1.094 \pm 0.096$ & $1.088 \pm 0.096$ & 0.326 \\
\hline $\begin{array}{l}\text { Lumbar spine } \\
\text { BMD }\left(\mathrm{g} / \mathrm{cm}^{2}\right)\end{array}$ & $1.001 \pm 0.150$ & $0.992 \pm 0.151$ & 0.337 \\
\hline Leptin (ng/ml) & $11.55 \pm 6.00$ & $10.69 \pm 4.66$ & 0.297 \\
\hline $\begin{array}{l}\text { Adiponectin } \\
(\mu \mathrm{g} / \mathrm{ml})\end{array}$ & $16.17 \pm 6.01$ & $18.56 \pm 7.17$ & 0.034 \\
\hline Ghrelin (pg/ml) & $1035.4 \pm 426.4$ & $1028.0 \pm 377.7$ & 0.890 \\
\hline
\end{tabular}

BMI, body mass index; FM, fat mass; FFM, fat-free mass; BMC, bone mineral content and BMD, bone mineral density.

and after the 12-month study period are presented in Table 1. Significant $(P<0.05)$ decreases in FFM (by 2.56\%) and BMC (by 1.63\%) and increases in adiponectin (by $14.8 \%$ ) were seen as a result of the 12-month study period. In addition, a non-significant $(P>0.05)$ decrease in total BMD (by 0.93\%), femoral neck BMD (by 0.45\%) and lumbar spine BMD (by 1.01\%) occurred during the 1-year study period. The decreases in measured BMD values were smaller with respect to the calculated LSC of $3 \%$.

Table 2 Pearson correlation coefficients of change ( $\Delta$ scores) in bone mineral values during a 12-month study period with baseline body composition and blood biochemical variables $(n=35)$.

\begin{tabular}{|c|c|c|c|c|}
\hline Variables & $\begin{array}{c}\Delta \text { Total } \\
\text { body BMC }\end{array}$ & $\begin{array}{c}\Delta \text { Total } \\
\text { body BMD }\end{array}$ & $\begin{array}{l}\Delta \text { Femoral } \\
\text { neck BMD }\end{array}$ & $\begin{array}{r}\Delta \text { Lumbar } \\
\text { spine BMD }\end{array}$ \\
\hline Height $(\mathrm{cm})$ & -0.144 & -0.171 & -0.189 & -0.152 \\
\hline $\begin{array}{l}\text { Body mass } \\
(\mathrm{kg})\end{array}$ & -0.231 & -0.117 & -0.150 & -0.225 \\
\hline $\mathrm{BMI}\left(\mathrm{kg} / \mathrm{m}^{2}\right)$ & -0.195 & -0.081 & -0.137 & -0.150 \\
\hline FM (kg) & $-0.359^{*}$ & -0.213 & $-0.337^{\star}$ & -0.207 \\
\hline $\begin{array}{l}\text { Trunk fat } \\
\text { (kg) }\end{array}$ & $-0.375^{\star}$ & -0.119 & -0.143 & -0.213 \\
\hline $\begin{array}{l}\text { Trunk fat: } \\
\text { leg fat ratio }\end{array}$ & -0.259 & -0.159 & -0.207 & $-0.337^{\star}$ \\
\hline FFM (kg) & -0.166 & -0.324 & -0.141 & -0.208 \\
\hline $\begin{array}{l}\text { Leptin } \\
\text { (ng/ml) }\end{array}$ & -0.244 & $-0.342^{*}$ & -0.316 & -0.154 \\
\hline $\begin{array}{l}\text { Adiponectin } \\
(\mu \mathrm{g} / \mathrm{ml})\end{array}$ & $0.348^{*}$ & 0.095 & 0.140 & $0.391^{*}$ \\
\hline $\begin{array}{l}\text { Ghrelin } \\
\text { (pg/ml) }\end{array}$ & 0.243 & 0.186 & 0.147 & 0.163 \\
\hline
\end{tabular}

$\mathrm{BMC}$, bone mineral content; BMD, bone mineral density; BMI, body mass index; FM, fat mass and FFM, fat-free mass.

${ }^{\star}$ Statistically significant; $P<0.05$.
Table 3 Predictive models with baseline variables explaining the variance in changes in bone mineral measures ( $\Delta$ scores) over a 12-month study period.

\begin{tabular}{lcc}
\hline Variables & $\begin{array}{c}\boldsymbol{B} \text { coefficient } \\
\pm \text { s.E.M. }\end{array}$ & $\boldsymbol{P}$ value \\
\hline$\Delta$ Total BMC $\left(R^{2}=0.306\right)$ & & \\
FM & $0.004 \pm 0.001$ & 0.015 \\
Adiponectin & $-0.003 \pm 0.002$ & 0.034 \\
$\Delta$ Total BMD $\left(R^{2}=0.206\right)$ & $0.004 \pm 0.001$ & 0.011 \\
FFM & $0.001 \pm 0.001$ & 0.045 \\
Leptin & $0.001 \pm 0.002$ & 0.043 \\
Femoral neck BMD $\left(R^{2}=0.102\right)$ & $0.001 \pm 0.001$ & 0.049 \\
FM & $0.029 \pm 0.013$ & 0.037 \\
Leptin & $-0.002 \pm 0.001$ & 0.044 \\
Trumbar spine BMD $\left(R^{2}=0.131\right)$ & \\
Adiponectin fat: ratio &
\end{tabular}

BMC, bone mineral content; FM, fat mass; BMD, bone mineral density and FFM, fat-free mass.

Changes in total BMC were significantly related to baseline FM, trunk fat and adiponectin values, while changes in total BMD correlated negatively with baseline leptin value (Table 2). Changes in femoral neck BMD were correlated with baseline FM, while changes in lumbar spine BMD were related to baseline trunk fat:leg fat ratio and adiponectin parameters.

Backward multiple linear regression analysis revealed that the independent variables that were significantly associated with decreases in total BMC in the multivariate analysis were baseline $\mathrm{FM}$ and adiponectin explaining $30.6 \%\left(R^{2} \times 100\right)$ of the total variance (Table 3). In another model, baseline FFM and leptin were the independent variables that explained 20.6\% $(P<0.05)$ of the total variance in the decreases in total BMD value. The variables in the multiple regression model, which were associated with decreases in femoral neck BMD, were FM and leptin $\left(R^{2}=0.102 ; P<0.05\right)$, while the independent variables were baseline trunk fat:leg fat ratio and adiponectin in the model with decreases in lumbar spine BMD as the dependent variable, and accounted for $13.1 \%(P<0.05)$ of the decreases in lumbar spine BMD variance.

\section{Discussion}

Different body composition and hormonal factors may predict a decrease in bone mineral values in healthy physically active older women. Our 12-month prospective study demonstrated significant decreases in FFM and BMC values and increases in adiponectin concentrations. However, decreases in total and areal BMD values were not significant and were smaller with respect to the calculated LSC (i.e. 20). It appeared that initial adiponectin concentration together with specific body composition characteristics was a significant predictor of a decrease in BMC and lumbar spine BMD values as a result of the 12-month observation period. 
While initial leptin concentration together with specific body composition parameters determined a decrease in total and femoral neck BMD values.

The results of the present study confirm the wellestablished influence of leptin on bone tissue reported in postmenopausal women $(3,21,22)$. The decrease in total BMD as a result of the 1-year study period was related to basal leptin concentration $(r=-0.342$; $P<0.05)$. Moreover, leptin together with FFM characterised $20.6 \%$ of the total variance in the loss of total BMD value, while leptin together with FM characterised $10.2 \%$ of the total variance in the loss of femoral neck BMD value in elderly women. Therefore, a low amount of FFM can be assumed to be associated with increased BMD loss and the development of osteoporosis in postmenopausal women (23). Similarly, FFM was also an independent variable to characterise leptin and BMD relationship in our previous study with healthy older women (11). These results together indicate that leptin exerts a positive effect on the protection of BMD loss in healthy physically active older women. However, it appears that there is no influence of leptin on BMD without specific body composition values in postmenopausal women $(11,21,24)$.

To our knowledge, this is the first study which has reported that a decrease in total BMC (by $1.63 \%$; $P<0.05$ ) and lumbar spine BMD (by $1.01 \% ; P>0.05$ ) was associated with baseline adiponectin concentration in healthy older women during a 12-month prospective study period. In addition, adiponectin and FM together characterised $30.6 \%$ of the total variance of the loss in total BMC value, while adiponectin together with trunk fat:leg fat ratio characterised $13.1 \%$ of the total variance of the loss in lumbar spine BMD value. These results demonstrate that negative changes in bone mineral parameters that occur during healthy ageing in older postmenopausal women are determined, at least in part, by initial adiponectin concentration. In support of our findings, the association between adiponectin concentration and measured bone mineral values has been reported in women $(3,11,25)$. However, the relationship between adiponectin and measured bone mineral values was controlled by the amount of FFM in healthy older women (11), while an independent effect of plasma adiponectin levels on BMD has been reported in middle-aged premenopausal women (8). Adiponectin and its receptors are expressed in human osteoblast-like cells (26) and single-nucleotide T45G polymorphism in exon 2 of the adiponectin gene has been found to be associated with lumbar spine BMD in women (27). In addition, a recent study demonstrated that adiponectin was related to bone alkaline phosphatase in elderly men (28). These results together support the hypothesis that adiponectin plays an important role in the maintenance of total BMC and regional BMD in healthy physically active older women.

Similar to the results of the previous studies with older adults (29), circulating ghrelin concentration was not associated with changes in any measured bone mineral values as a result of the 1-year study period in healthy physically active postmenopausal women. This suggests that ghrelin concentration in blood is not an important parameter in predicting the loss of bone mineral values in ageing women. By contrast, previous studies have demonstrated that ghrelin may, in part, mediate some of the protective effect of the adipose tissue on the skeleton in older men (28) and women (11). However, by adjusting the data for markers of central obesity, the association between plasma ghrelin and bone mineral values was lost in older women (11). In addition, in vitro study by Maccarinelli et al. (30) showed that ghrelin administration increased osteoblast proliferation in cell cultures and increases the levels of bone formation markers. These results demonstrate that ghrelin may play some role in total BMC and regional BMD, but does not appear to be a determinant in the loss of bone mineral values during ageing in healthy older women.

The results of the present investigation demonstrated that adiponectin concentration was significantly increased in the elderly physically active healthy women after the 12-month prospective study. This is in accordance with the previous studies that have demonstrated that adiponectin concentration is positively related to age in pre- and postmenopausal women $(3,16)$. It has previously been suggested that the significant relationship of adiponectin with age is the result of the changes in body composition $(16,31)$. Indeed, significant decreases in FFM and BMC values were seen in our physically active older women during the 1-year study period.

In conclusion, the results of the present study show a complex interaction of specific body composition parameters with leptin, adiponectin and ghrelin. The decrease in total BMC and lumbar spine BMD is characterised by initial adiponectin and specific body composition parameters, while the decrease in total and femoral neck BMD is characterised by leptin and specific body composition parameters. In addition, FFM appears to be an important determinant of decrease in total BMD in healthy physically active women. However, the selection of a healthy population and a relatively small number of subjects are not representative of the general population of the same age. Therefore, further interventional studies are necessary to clarify the exact role of these adipocytokines and ghrelin in the regulatory specificities of bone and mineral metabolism.

\section{Declaration of interest}

There is no conflict of interest that could be perceived as prejudicing the impartiality of the research reported.

\section{Funding}

This study was supported by Estonian Science Foundation Grant GKKSP 6638. 


\section{Acknowledgements}

We would like to thank all of the women who participated in this study.

\section{References}

1 Felson DT, Zhang Y, Hannan MT \& Anderson JJ. Effects of weight and body mass index on bone mineral density in men and women: the Framingham study. Journal of Bone and Mineral Research 1993 8 567-573.

2 Jürimäe J \& Jürimäe T. Influence of insulin-like growth factor-1 and leptin on bone mineral content in healthy premenopausal women. Experimental Biology and Medicine 2006231 1673-1677.

3 Jürimäe J \& Jürimäe T. Plasma adiponectin concentration in healthy pre- and postmenopausal women: relationship with body composition, bone mineral, and metabolic variables. American Journal of Physiology. Endocrinology and Metabolism 2007293 E42-E47.

4 Harris S, Dallal GE \& Dawson-Hughes B. Influence of body weight on rates of change in bone density of the spine, hip, and radius in postmenopausal women. Calcified Tissue International 199250 19-23.

5 Ravn P, Cizza G, Bjarnason NH, Thompson D, Daley M, Wasnich RD, McClung M, Hosking D, Yates AJ \& Christiansen C. Low body mass index is an important risk factor for low bone mass and increased bone loss in early postmenopausal women. Journal of Bone and Mineral Research 199914 1622-1627.

6 Bertoli S, Magni P, Krogh V, Ruscica M, Dozio E, Testolin G \& Battezzati A. Is ghrelin a signal of decreased fat-free mass in elderly subjects? European Journal of Endocrinology 2006155 321-330.

7 Jürimäe J, Rembel K, Jürimäe T \& Rehand M. Adiponectin is associated with bone mineral density in perimenopausal women. Hormone and Metabolic Research 200537 297-302.

8 Jürimäe $\mathrm{J} \&$ Jürimäe T. Adiponectin is a predictor of bone mineral density in middle-aged premenopausal women. Osteoporosis International $2007 \mathbf{1 8} 1253-1259$.

9 Reid IR. Relationships among body mass, its compartments, and bone. Bone 200231 547-555.

10 Douchi T, Yamamoto S, Kuwahata R, Oki T, Yamasaki H \& Nagata Y. Effects of non-weight-bearing fat on bone mineral density in normal postmenopausal women - a key role for fat mass. Obstetrics and Gynecology 200096 13-17.

11 Jürimäe J, Jürimäe T, Leppik A \& Kums T. The influence of ghrelin, adiponectin and leptin on bone mineral density in healthy postmenopausal women. Journal of Bone and Mineral Metabolism 200826 618-623.

12 Meier U \& Grassner AM. Endocrine regulation of energy metabolism: review of pathobiochemical and clinical chemical aspects of leptin, ghrelin, adiponectin, and resistin. Clinical Chemistry 200450 1511-1525.

13 Weyer C, Funahashi T, Tanaka S, Hotta K, Matsuzawa Y, Pratley RE \& Tataranni PA. Hypoadiponectemia in obesity and type 2 diabetes: close association with insulin resistance and hyperinsulinemia. Journal of Clinical Endocrinology and Metabolism 200186 1930-1935.

14 Tschop M, Smiley DL \& Heiman ML. Ghrelin induces adiposity in rodents. Nature $2000 \mathbf{4 0 7} 908-913$.

15 Nakazato M, Murakami N, Date Y, Kojima M, Matsuo H, Kangawa K \& Matsukura S. A role for ghrelin in the central regulation of feeding. Nature 2001409 194-198.

16 Gavrila A, Chan JL, Yiannakouris N, Kontogianni M, Miller LC, Orlova C \& Mantzoros CS. Serum adiponectin levels are inversely associated with overall and central fat distribution but are not directly regulated by acute fasting or leptin administration in humans: cross-sectional and interventional studies. Journal of Clinical Endocrinology and Metabolism $2003 \mathbf{8 8} 4823-4831$.
17 Sowers MFR, Wildman RP, Mancuso P, Eyvazzadeh AD, KarvonenGutierrez CA, Rillamas-Sun E \& Jannausch ML. Change in adipocytokines and ghrelin with menopause. Maturitas 200859 149-157.

18 Kontogianni MD, Dafni UG, Routsias JG \& Skopouli FN. Blood leptin and adiponectin as possible mediators of the relation between fat mass and BMD in perimenopausal women. Journal of Bone and Mineral Research 200419 546-554.

19 Garnett SP, Högler W, Blades B, Baur LA, Peat J, Lee J \& Cowell CT. Relation between hormones and body composition, including bone, in prepubertal children. American Journal of Clinical Nutrition 200480 966-972.

20 Gallagher JC, Rosen CJ, Chen P, Misurski DA \& Marcus R. Response rate of bone mineral density to teriparatide in postmenopausal women with osteoporosis. Bone $2006391268-1275$.

21 Blain H, Vuillemin A, Guillemin F, Durant R, Hanesse B, De Talance N, Doucet B \& Jeandel C. Serum leptin level is a predictor of bone mineral density in postmenopausal women. Journal of Clinical Endocrinology and Metabolism $2002 \mathbf{8 7}$ 1030-1035.

22 Zhong N, Wu XP, Xu ZR, Wang AH, Luo XH, Cao XZ, Xie H, Shan PF \& Liao EY. Relationship of serum leptin with age, body weight, body mass index, and bone mineral density in healthy mainland Chinese women. Clinica Chimica Acta 2005351 161-168.

23 Kirchengast S, Peterson B, Hauser G \& Knogler W. Body composition characteristics are associated with the bone density of the proximal femur end in middle- and old-aged women and men. Maturitas $200139133-145$.

24 Martini G, Valenti R, Giovani S, Franci B, Campagna S \& Nuti R. Influence of insulin-like growth factor-1 and leptin on bone mass in healthy postmenopausal women. Bone 200128 113-117.

25 Misra M, Miller KK, Cord J, Prabhakaran R, Herzog DB, Goldstein M, Katzman DK \& Klibanski A. Relationships between serum adipokines, insulin levels, and bone density in girls with anorexia nervosa. Journal of Clinical Endocrinology and Metabolism $2007922046-2052$.

26 Berner HS, Lyngstadaas SP, Spahr A, Monjo M, Thommesen L, Drevon CA, Syversen U \& Reseland JE. Adiponectin and its receptors are expressed in bone-forming cells. Bone 200435 842-849.

27 Lee WY, Rhee EJ, Oh KW, Kim SY, Jung CH, Yun EJ, Bae KH, Kang MI \& Kim SW. Identification of adiponectin and its receptors in human osteoplast-like cells and association of T45G polymorphism in exon 2 of adiponectin gene with lumbar spine bone mineral density in Korean women. Clinical Endocrinology $2006 \mathbf{6 5}$ 631-637.

28 Gonnelli S, Caffarelli C, Del Santo K, Cadirni A, Guerriero C, Lucani B, Franci B \& Nuti R. The relationship of ghrelin and adiponectin with bone mineral density and bone turnover markers in elderly men. Calcified Tissue International $2008 \mathbf{8 3} 55-60$.

29 Weiss LA, Langenberg C \& Barret-Connor E. Ghrelin and bone: is there an association for older adults?: the Rancho Bernardo study Journal of Bone and Mineral Research 200621 752-757.

30 Maccarinelli G, Sibilia V, Torsello A, Raimondo F, Pitto M, Giustina A, Netti C \& Cocchi D. Ghrelin regulates proliferation and differentation of osteoblastic cells. Journal of Endocrinology $2005184249-256$.

31 Cnop M, Havel PJ, Utzschneider KM, Carr DB, Sinha MK, Boyko EJ, Retzlaff BM, Knopp RH, Brunzell JD \& Kahn SE. Relationship of adiponectin to body fat distribution, insulin sensitivity and plasma lipoproteins: evidence for independent roles of age and sex. Diabetologia $2003 \mathbf{4 6} 459-469$.

Received 10 November 2008

Accepted 2 December 2008 